\title{
Fast sulfur dioxide measurements correlated with cloud condensation nuclei spectra in the marine boundary layer
}

\author{
D. C. Thornton ${ }^{1}$, A. R. Bandy ${ }^{1}$, and J. G. Hudson ${ }^{2}$ \\ ${ }^{1}$ Department of Chemistry, Drexel University, Philadelphia, PA, USA \\ ${ }^{2}$ Desert Research Institute, Nevada System of Higher Education, Reno, NV, USA
}

Received: 2 May 2011 - Published in Atmos. Chem. Phys. Discuss.: 17 May 2011

Revised: 26 October 2011 - Accepted: 9 November 2011 - Published: 21 November 2011

\begin{abstract}
During the Rain in (shallow) Cumulus over the Ocean (RICO) project simultaneous high rate sulfur dioxide $\left(\mathrm{SO}_{2}\right)$ measurements and cloud condensation nuclei $(\mathrm{CCN})$ spectra were made for the first time. For research flight 14 (14 January 2005) the convective boundary layer was impacted by precipitation and ship plumes for much of the midday period but not in the late afternoon. Number densities of accumulation mode aerosols ( 0.14 to $0.2 \mu$ m diameter) were a factor of two greater in the later period while $\mathrm{CCN}$ were $35 \%$ to $80 \%$ greater for aerosols that activate at supersaturations $>0.1 \%$. Linear correlations of $\mathrm{SO}_{2}$ and $\mathrm{CCN}$ were found for $\mathrm{SO}_{2}$ concentrations ranging from 20 to 600 partsper-trillion (pptv). The greatest sensitivities were for $\mathrm{SO}_{2}$ and $\mathrm{CCN}$ that activate at supersaturations $>0.1 \%$ for both clean and polluted air. In a region unaffected by pollution $\mathrm{SO}_{2}$ was linearly correlated only with $\mathrm{CCN}$ at $>0.2 \%$ supersaturation. These correlations imply that the smallest CCN may be activated by $\mathrm{SO}_{2}$ through heterogeneous conversion. Evidence for entrainment of $\mathrm{CCN}$ from the cloud layer into the CBL was found.
\end{abstract}

\section{Introduction}

The Rain in (shallow) Cumulus over the Ocean (RICO) project was an intensive study of shallow cumulus clouds within the trade wind (TW) inversion (Rauber et al., 2007b). The field program was designed so that continuous radar measurements to detect precipitation were combined with intensive physical and chemical measurements obtained with several aircraft and a ship operating within the radar domain and primarily upwind of the radar site. A primary goal of

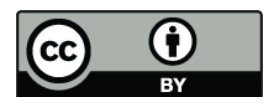

Correspondence to: D. C.Thornton (dct@drexel.edu)
RICO was to understand the conditions that exist at the onset of precipitation in the shallow cumulus clouds of the TW regime.

Several studies have considered factors that could be dominant in forming cloud drops during RICO: low level wind speeds and aerosol size distributions (Colon-Robles et al., 2006), cloud condensation nuclei (CCN) and updraft velocities (Hudson and Mishra, 2007); (Hudson et al., 2009), giant and ultragiant CCN (Arthur et al., 2010; Colon-Robles et al., 2006; Lowenstein et al., 2010; Reiche and Lasher-Trapp, 2010; Hudson et al., 2011) and the submicron sized aerosols (Lowenstein et al., 2010). Gerber et al. (2008) point out these studies inferred the importance of subcloud aerosol measurements and near cloud base concentrations of droplets but neglected processes in the upper portions of the clouds including entrainment of environmental air above the convective boundary layer (CBL).

This study presents a more detailed investigation of the subcloud aerosol distributions and their relationship to sulfur dioxide $\left(\mathrm{SO}_{2}\right) . \mathrm{SO}_{2}$ is a precursor to the formation of sulfate aerosols that are considered important in forming and modifying aerosols that could become $\mathrm{CCN}$ as well as modifying the number concentrations and size distributions of cloud droplets. The RICO project was the first time that $\mathrm{CCN}$ supersaturation spectra and high rate ( $25 \mathrm{~Hz}$ sampling), continuously calibrated, high sensitivity $\mathrm{SO}_{2}$ measurements were made simultaneously. In addition, $\mathrm{SO}_{2}$ measurements were fast enough to estimate its flux to the surface by the eddy correlation technique. $\mathrm{SO}_{2}$ measurements within clouds were also obtained that can be evaluated with respect to droplet concentrations.

Research flight 14 (RF14, 14 January 2005) of the National Center for Atmospheric Research (NCAR) C-130 was typical of many of the RICO C-130 flights with respect to the $\mathrm{SO}_{2}$ concentrations. Plumes of $\mathrm{SO}_{2}$ on the order of tens of $\mathrm{km}$ long were often encountered during the first circular

Published by Copernicus Publications on behalf of the European Geosciences Union. 
flight track in the CBL near the surface. The most likely sources of these plumes were ships, which were occasionally observed visually. While RICO was considered "clean" for aerosol concentrations compared to continental or near shore conditions, the $\mathrm{SO}_{2}$ concentrations were much higher than those encountered in the central Pacific CBL (Thornton et al., 1999; Bandy et al., 1996).

The $\mathrm{SO}_{2}$ plumes in the CBL during the early part of RF14 were remarkable in their magnitude and areal extent for a region expected to be clean with a long fetch of TW. Peak $\mathrm{CBL} \mathrm{SO} \mathrm{S}_{2}$ concentrations reached $600 \mathrm{pptv}$ and concentrations $>100 \mathrm{pptv}$ were pervasive in the CBL. During flight legs at 800 and $1300 \mathrm{~m}$ above sea level (a.s.l.) devoted to in situ sampling of the shallow cumulus clouds within the TW inversion, numerous encounters of $\mathrm{SO}_{2}>100 \mathrm{pptv}$ within the clouds were observed. In contrast, $\mathrm{SO}_{2}$ concentrations above the CBL outside of clouds, but below the TW inversion, were $<35$ pptv except for a few short encounters with aircraft exhaust. The descriptions of the $\mathrm{SO}_{2}$ in clouds are the subject of another paper.

\section{Measurements}

The suite of chemical measurements for RICO was limited in that the program was devoted to understanding the initiation of precipitation in the warm shallow cumulus clouds. The $\mathrm{C}-130$ chemistry data set, in addition to $\mathrm{SO}_{2}$, included dimethyl sulfide (DMS), ozone $\left(\mathrm{O}_{3}\right)$, water vapor, hydrogen peroxide $\left(\mathrm{H}_{2} \mathrm{O}_{2}\right)$, and methyl hydroperoxide $\left(\mathrm{CH}_{3} \mathrm{O}_{2} \mathrm{H}\right)$. The sampling rates for all these gases were $25 \mathrm{~s}^{-1}$ except for the peroxides although detector noise limited DMS data to $1 \mathrm{~s}^{-1}$. The $\mathrm{C}-130$ physics data set included CCN spectrometers from Desert Research Institute (DRI) (Hudson and Mishra, 2007; Hudson et al., 2009), the standard set of NCAR atmospheric state measurements, condensation nuclei $(\mathrm{CN})$ counters, probes for aerosols (PCASP-200), cloud droplets (FSSP-100), and hydrometeors (260-X, 2DC, 2DP). Throughout the RICO project the NCAR S-band $(10 \mathrm{~cm})$ radar was running nearly continuously, which provided a look at the precipitation conditions upwind in the hours prior to and during the aircraft flights. The full suite of the instruments and measurements employed has been described in a supplement to the RICO overview paper (Rauber et al., 2007a).

The $\mathrm{SO}_{2}$ measurements during RICO were obtained using an atmospheric pressure ionization mass spectrometer (APIMS) with continuous calibration using isotopically labeled sulfur dioxide $\left({ }^{34} \mathrm{SO}_{2}\right)$ added to the sampled air (Thornton et al., 2002). The power of this technique lies not only in the signal calibration but in the continuous indication of the performance of the APIMS in terms of sensitivity and response times under all operating conditions (Bandy et al., 1993). A blank determination was obtained using about $50 \mathrm{~cm}$ of $6 \mathrm{~mm}$ copper tubing, which removed 500 to
$800 \mathrm{pptv} \mathrm{SO}_{2}$ with a $1 / \mathrm{e}$ time of $0.58 \mathrm{~s}$. Sampling at $25 \mathrm{~Hz}$ allows determination of $\mathrm{SO}_{2}$ on a physical scale of $10 \mathrm{~m}$. This is a great advantage for detecting $\mathrm{SO}_{2}$ at the transitions near the cloud edges as well as variations within clouds related to the physical dynamics of the clouds. In addition, the fast response allowed detection of transients of $\mathrm{SO}_{2}$ produced by aircraft and ship exhausts.

The typical C-130 flight patterns were divided between circular tracks in the CBL (Table 1) and the free troposphere (FT) regions and directed cloud sampling as frequently as possible. An initial 30 min circular track (FT1) was flown above the TW inversion in the region of interest. During this segment dropsondes were released periodically around the track to give a preview of the TW layer meteorological conditions. After descent to about $90 \mathrm{~m}$ a.s.l., a $30 \mathrm{~min}$ circular track (SU1, see Table 1) was flown followed by a sub cloud base circle (SC) about $450 \mathrm{~m}$ a.s.l. The starting locations of the CBL circles were approximately colocated and flown with opposite rotations. All the circles were advected with the mean wind with respect to the starting location.

Following the CBL circles, 3 to $4 \mathrm{~h}$ were devoted to sampling in and around clouds within the TW inversion. Altitudes for cloud sampling were determined by the depth of clouds for that flight with an effort to provide a representative sampling of different levels of cloud development. The remaining flight time was spent by repeating the sub-cloud base circle (SC2), a surface circle (SU2), and ascent to a final circle in the free troposphere (FT2) with dropsondes deployed as before.

\section{Discussion}

The RICO flight program was designed for a detailed study of clouds and precipitation using in situ measurements and remote sensing of the region defined by the radar domain. This strategy effectively made the experiment an Eulerian one, although each circle in the CBL and the FT was drifted with the wind in a Lagrangian mode. While RICO was not a process study, the 4 to $5 \mathrm{~h}$ time step between the initial and ending CBL circles allows some inferences to be made about the chemistry and evolution of aerosols as the day progressed. Given the long upwind fetch in a trade wind region of relative consistency, this may be a good assumption with regard to the chemistry and aerosol physics.

With the RICO domain in the TW regime to the north and east of Antigua and Barbuda, advection of air parcels relatively free of anthropogenic impacts from long range was expected. For RF14 the wind direction near the surface was about $75^{\circ}$ at 12 to $16 \mathrm{~m} \mathrm{~s}^{-1}$ throughout the flight, except near the beginning and end positions of SU1 where wind speeds were 8 to $13 \mathrm{~m} \mathrm{~s}^{-1}$. The cloud layer had winds about $90^{\circ}$ about $15 \mathrm{~m} \mathrm{~s}^{-1}$ except near $2 \mathrm{~km}$ a.s.l. where the wind speeds were $\sim 13 \mathrm{~m} \mathrm{~s}^{-1}$. RF 14 had the highest average winds for the RICO program. The first low circles (SU1 and SC1) were 
Table 1. Start times of CBL circles for RICO RF14.

\begin{tabular}{lll}
\hline SU1 & Initial surface circle at $90 \mathrm{~m}$ & 16:12:19 UTC* \\
SC1 & Initial sub-cloud circle at $450 \mathrm{~m}$ & 16:49:04 UTC \\
SU2 & Final surface circle at $90 \mathrm{~m}$ & $21: 46: 39$ UTC \\
SC2 & Final sub-cloud circle at $450 \mathrm{~m}$ & 21:09:49 UTC \\
\hline
\end{tabular}

* Local time is UTC-4.

affected by several periods of cooler temperatures due to evaporative cooling of rain (cold pool effect), which also resulted in decreased turbulence indicated by the vertical wind component.

One advantage of the RICO project was that the S-band radar was running nearly continuously throughout the experimental period. In the absence of a Lagrangian mode process study, the radar data provide a look at the precipitation conditions upwind in the hours prior to and during the aircraft flight. To estimate the influence that precipitation may have had on $\mathrm{SO}_{2}$ and aerosols observed during the low altitude circles, every point along the CBL flight tracks was advected back in time using the $u$ and $v$ component winds for each second along the track to the time of the $0.5^{\circ}$ elevation radar scan. A composite of the time series of the advected tracks superimposed on the radar plots can then be viewed to follow the development of potential precipitation impacts.

Inspection of the time series of the back advected aircraft tracks for the SU1 and SC1 showed that the beginning and ending parts of these circles were affected by precipitation for nearly the entire time ( 1 to $1.5 \mathrm{~h}$ ) the air parcels were within the radar range. The central portions of these two CBL circles were free of precipitation for the entire time the parcels were within the radar range. It was these central portions of the CBL tracks that had a doubling of the accumulation mode aerosols between the beginning and the end of the flight (Table 3 and Fig. 4). Unfortunately, portions of these central sections were also impacted by the ship plumes for the SU1 and SC1 circles, which limited the data for direct comparisons of $\mathrm{SO}_{2}$ and aerosols for the entire period. The radar plots and the back advected tracks for the late afternoon did not indicate any precipitation for the SU2 and SC2 circles although the cloud cover was similar to the earlier CBL circles.

\subsection{Vertical gradients}

A distinguishing feature of the CBL is that scalars are well mixed from near the surface to the top of the layer defined by the turbulence in the CBL. The simplest case is a one layer system like the cloud topped stratocumulus BL. The TW regime can be described as a two layer system where the well mixed CBL is topped by an intermittently mixed layer with clouds extending as far as the TW inversion. Precipitation and the effects of evaporating precipitation (cold pool effect) can disrupt the usually well mixed CBL of the TW regime. The cold pools are marked by decreases in equivalent potential temperature $\left(\Theta_{\mathrm{e}}\right)$ and decreases in turbulence compared to the warmer $\mathrm{CBL}$ air.

RF14 was similar to many RICO flights in the CBL with $\mathrm{SO}_{2}$ concentrations typical of northern hemisphere marine CBL (Thornton et al., 1993; Tu, 2004) but atypical of a remote TW CBL in the Pacific (Thornton et al., 1999). Although the region appeared free of the impacts of continental sources, numerous ships transited the area (Capaldo et al., 1999) as well as the presence of the R/V Seward Johnson, which provided a platform for a cloud radar and a wind profiler. For RF14 this impacted area included the starting and ending portions of the CBL circles (between $61.1^{\circ} \mathrm{W}$ to $62.1^{\circ} \mathrm{W}$ and $17.7^{\circ} \mathrm{N}$ to $18.1^{\circ} \mathrm{N}$ ). During the SU1 circle of $\mathrm{RF} 14 \mathrm{SO}_{2}$ concentrations were as high as 597 pptv (Fig. 1) and vertical mixing in the $\mathrm{CBL}$ resulted in $\mathrm{SO}_{2}>100 \mathrm{pptv}$ as high as $500 \mathrm{~m}$ a.s.l. (Fig. 2). Convection in the CBL also resulted in $\mathrm{SO}_{2}>100 \mathrm{pptv}$ within small cumulus clouds at $800-1300 \mathrm{~m}$ a.s.l. This convection of $\mathrm{SO}_{2}$ occurred over the portion of RF14 where the most precipitation was observed by the S-band radar for the CBL circles.

For the section of the SU1 and SC1 circles where the pollution plumes and precipitation were absent, a vertical gradient was observed with a $27 \%$ decrease in the mean $\mathrm{SO}_{2}$ from $90 \mathrm{~m}$ to $450 \mathrm{~m}$ (Table 2). At the same time there was also a marked vertical gradient for the mean DMS with $85 \mathrm{pptv}$ for SU1 and $55 \mathrm{pptv}$ for $\mathrm{SC} 1$. Water vapor mixing ratio (MR) and $\mathrm{O}_{3}$ concentrations showed no gradient within the $\mathrm{CBL}$ for this portion of the flight, and there was no apparent cold pool effect in this region for SU1 or SC1. Unfortunately, there was no $\mathrm{H}_{2} \mathrm{O}_{2}$ data for this period of SU1 to assess the gradient for this soluble gas species. Note that the aircraft vertical profile from $90 \mathrm{~m}$ to $470 \mathrm{~m}$ took place on the opposite side of the circles, which was where the precipitation had occurred. Based on the vertical wind velocity component and the MR during the climb in altitude, there appeared to be some disturbance to the CBL structure between $250 \mathrm{~m}$ and $400 \mathrm{~m}$.

The vertical gradient in $\mathrm{CN}$ for this same period had an $11 \%$ decrease between SU1 and SC1 (Table 2). CCN number concentrations had the opposite trend with an increase of $12 \%$ at $1.5 \%$ supersaturation (Fig. 5) with the largest contribution from $\mathrm{CCN}$ at supersaturations $\leq 0.1 \%$. The CCN number concentrations could account for $56 \%$ of $\mathrm{CN}$ concentrations for $\mathrm{SC} 1$ and for $45 \%$ of $\mathrm{CN}$ concentrations for SU1.

For the locations of SU2 and SC2 comparable to areas of SU1 and SC2 free of the pollution and precipitation, there was no vertical gradient in $\mathrm{SO}_{2}$ but $\mathrm{CN}$ had the same $11 \%$ decrease in concentrations with altitude as in the earlier CBL circles. However, the CCN number concentrations decreased with altitude by $6 \%$ at $1.5 \%$ supersaturation but by $14 \%$ at $0.04 \%$ supersaturation with the largest contribution from $\mathrm{CCN}$ at supersaturations $\leq 0.1 \%$ (Fig. 5). The $\mathrm{CCN}$ 
Table 2. NCAR CN number concentrations and $\mathrm{SO}_{2}$ concentrations for the CBL circles of RICO RF14 without direct effects of ship plumes and precipitation. Measurements of $\mathrm{CN}$ and $\mathrm{SO}_{2}$ sampled at $25 \mathrm{~s}^{-1}$ were integrated to $1 \mathrm{~s}$.

\begin{tabular}{lccccc}
\hline & \multicolumn{2}{c}{$\mathrm{CN}\left(\# \mathrm{~cm}^{-3}\right)$} & \multicolumn{2}{c}{$\mathrm{SO}_{2}$ (pptv) } \\
\hline Circle & Time into circle & Mean & Std. dev. & Mean & St. Dev. \\
\hline SU1 & 901 to $1200 \mathrm{~s}$ & 245 & 5.57 & 40.4 & 2.32 \\
SC1 & 980 to $1200 \mathrm{~s}$ & 218 & 6.05 & 29.2 & 1.76 \\
SU2 & 800 to $1100 \mathrm{~s}$ & 320 & 6.99 & 27.6 & 2.61 \\
SC2 & 501 to $1100 \mathrm{~s}$ & 283 & 5.10 & 28.5 & 2.19 \\
\hline
\end{tabular}

concentrations could account for $64 \%$ of $\mathrm{CN}$ concentrations for SC2 and $61 \%$ of CN concentrations for SU2. For the accumulation mode and larger aerosols (Fig. 3 and Table 2) there was no vertical gradient for either early or late CBL periods.

There could have been several sources of the observed vertical gradients. $\mathrm{SO}_{2}$ ranged from 20 to $35 \mathrm{pptv}$ in cloud free air above the CBL (excluding brief encounters with aircraft exhausts). However, dilution of $\mathrm{SO}_{2}$ in the $\mathrm{CBL}$ by entrainment of $\mathrm{SO}_{2}$ from the cloud layer would have been insufficient to produce the observed decrease in $\mathrm{SO}_{2}$ in the $<1$ hr time difference between the SU1 and $\mathrm{SC} 1$ measurements. The $\mathrm{SO}_{2}$ flux estimated by the eddy correlation technique was an upward $+0.51 \mathrm{pptv} \mathrm{m} \mathrm{s}^{-1}$ for this $\mathrm{SC} 1$ time period. This segment of SC1 had many more clouds overhead than during SU1. Because CN can be expected to be transported as gases would, loss of $\mathrm{SO}_{2}$ and $\mathrm{CN}$ to the cloud layer would be consistent with the data.

The greater relative decrease for $\mathrm{SO}_{2}$ compared to $\mathrm{CN}$ may indicate that there could be a chemical loss path as well as a transport loss path. The decrease of $\mathrm{SO}_{2}$ during this portion of $\mathrm{SC} 1$ and the increase in $\mathrm{CCN}$ may be the result of $\mathrm{CCN}$ formation and growth aided by $\mathrm{SO}_{2}$ oxidation. The primary oxidant for $\mathrm{SO}_{2}$ was likely $\mathrm{H}_{2} \mathrm{O}_{2}$, which had concentrations of 800-1000 pptv throughout the CBL for all the RF14 CBL circles, although there was no $\mathrm{H}_{2} \mathrm{O}_{2}$ data available for the period of SU1 discussed here.

\subsection{Time evolution}

The small increases in $\mathrm{CCN}$ concentrations in the vertical gradients during SC1 relative to SU1 were dwarfed by the much greater $\mathrm{CCN}$ concentrations for supersaturations $\geq 0.2 \%$ (Fig. 5) for both $\mathrm{SU} 2$ and $\mathrm{SC} 2$ compared to the earlier CBL circles. The increase in CCN in the CBL implies that the higher concentrations of $\mathrm{CCN}$ during SU2 and SC2 were a net result of increased production or input with loss mechanisms which were slow, diminished, or absent. The absence of gradients in $\mathrm{SO}_{2}, \mathrm{O}_{3}$, water vapor $\mathrm{MR}$, and $\mathrm{H}_{2} \mathrm{O}_{2}$
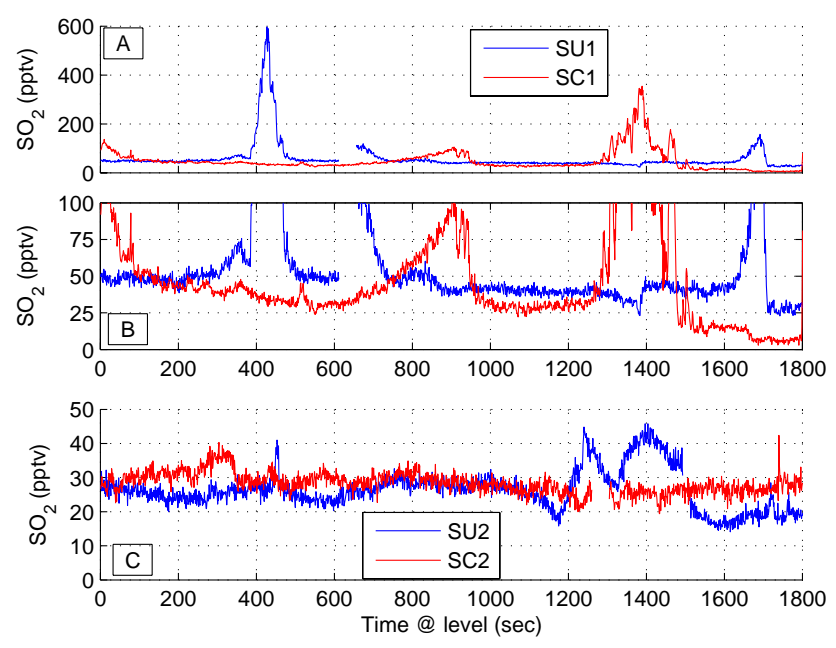

Fig. 1. $\mathrm{SO}_{2}(1 \mathrm{~Hz})$ time series for CBL circles of RICO RF14. Panel (B) shows an expanded scale of (A). Times are relative to the start times of circles given in Table 1 . The $\mathrm{SO}_{2}$ peak near $1400 \mathrm{~s}$ of SC1 is not the same one as the peak in near $450 \mathrm{~s}$ of SU1, which was $40 \mathrm{~km}$ downwind at the time of the peak in SC1.

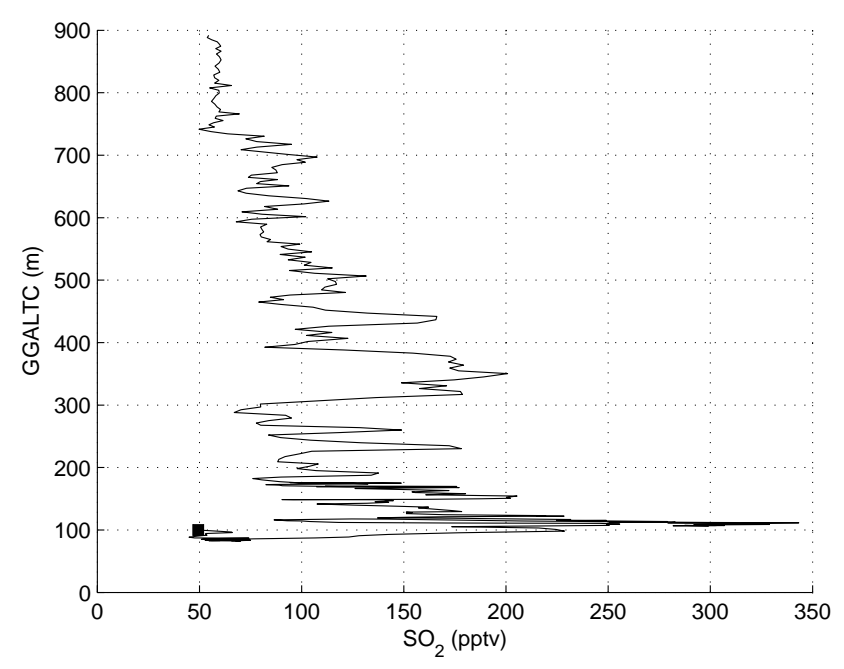

Fig. 2. Portion of the C-130 descent in clear air to the start of the first surface circle (filled square). $\mathrm{SO}_{2}>100 \mathrm{pptv}$ from probable ship plumes was mixed to $500 \mathrm{~m}$ a.s.l. Data obtained at 25 samples s $^{-1}$ were integrated to $1 \mathrm{~s}^{-1}$.

in the CBL for the later circles attest to the stability of the CBL for this period. Under these stable conditions, a major source of $\mathrm{CCN}$ production could be entrainment from the cloud layer of small aerosols which were modified by cloud processing, not removed by precipitation, and remained in the cloud layer after clouds had dissipated. The primary loss mechanism for CCN in the CBL is likely to be convection into the cloud layer.

These increases in $\mathrm{CCN}$ concentrations appeared to be related to the lack of precipitation (based on the radar scans) 
Table 3. Statistics for the PCASP-200 concentrations $\left(\# \mathrm{~cm}^{-3}\right)$ for sizes 0.14 to $2.75 \mu \mathrm{m}$ integrated for $1 \mathrm{~s}$ for the precipitation free periods 500 to $1200 \mathrm{~s}$ of each circle.

\begin{tabular}{lccc}
\hline Circle & Mean & Std. Dev. & Std. error of mean \\
\hline SU1 & 35.4 & 7.11 & 0.27 \\
SU2 & 69.1 & 10.5 & 0.40 \\
SC1 & 37.5 & 6.79 & 0.26 \\
SC2 & 65.2 & 9.13 & 0.34 \\
\hline
\end{tabular}

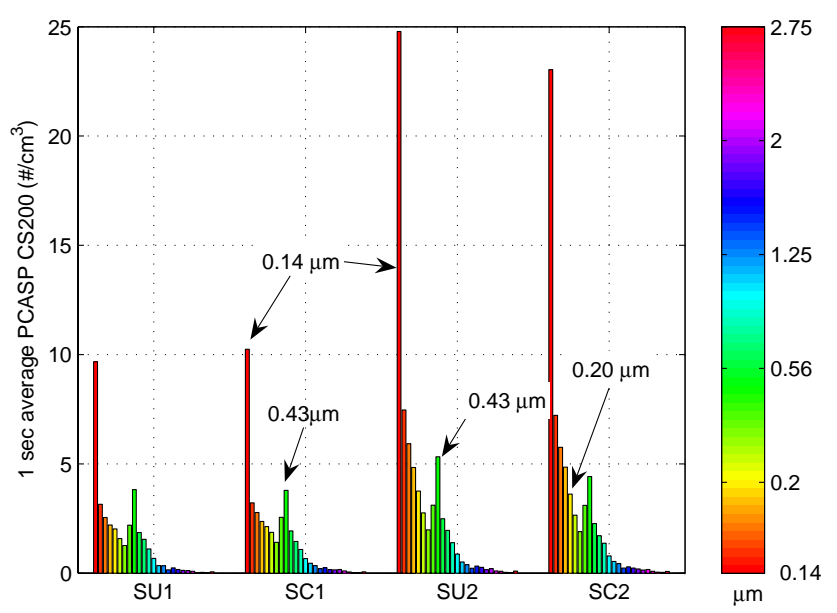

Fig. 3. Size spectra from $10 \mathrm{~Hz}$ PCASP-200 integrated over the 500 $\mathrm{s}$ to $1200 \mathrm{~s}$ portions of the CBL circles of RICO RF14 excluding the periods of precipitation and pollution.

during the hours prior to the measurements. Precipitation averaged over the radar domain during RICO was typically $<10 \%$ with an estimate of $\sim 15 \%$ for RF14 (Rauber et al., 2007b; Snodgrass et al., 2009). In the absence of precipitation it would be possible for entrainment to be a major source of $\mathrm{CCN}$ formed in the cloud layer and modified by cloud processing. It is unlikely that the large increase in $\mathrm{CCN}$ concentrations was due to any homogeneous or heterogeneous processes in the CBL within the $\sim 5 \mathrm{~h}$ time between SU1 and SU2. Most likely heterogeneous processes over a number of days would have produced this result. The CBL conditions for this portion of RF14 were much more like that observed in the central Pacific trade wind regime where $\mathrm{CCN}$ concentrations exceeded $300 \mathrm{~cm}^{-3}$ in a CBL with few clouds above and little or no precipitation (Hudson et al., 2009).

In the precipitation free areas the fluxes of $\mathrm{SO}_{2}$ at $90 \mathrm{~m}$ were $-0.34 \mathrm{pptv} \mathrm{m} \mathrm{s}^{-1}$ for SU1 and $-0.28 \mathrm{pptv} \mathrm{m} \mathrm{s}^{-1}$ for $\mathrm{SU} 2$, which would contribute a 9 pptv loss of $\mathrm{SO}_{2}$ to the surface (the sea or aerosols) for the $\sim 5 \mathrm{~h}$ time between $\mathrm{SU} 1$ and SU2 for an observed CBL depth of $\sim 600 \mathrm{~m}$. This difference was nearly equal to the decrease of the mean pollution free $\mathrm{SO}_{2}$ concentrations from $40 \mathrm{pptv}$ to $29 \mathrm{pptv}$, respectively, for
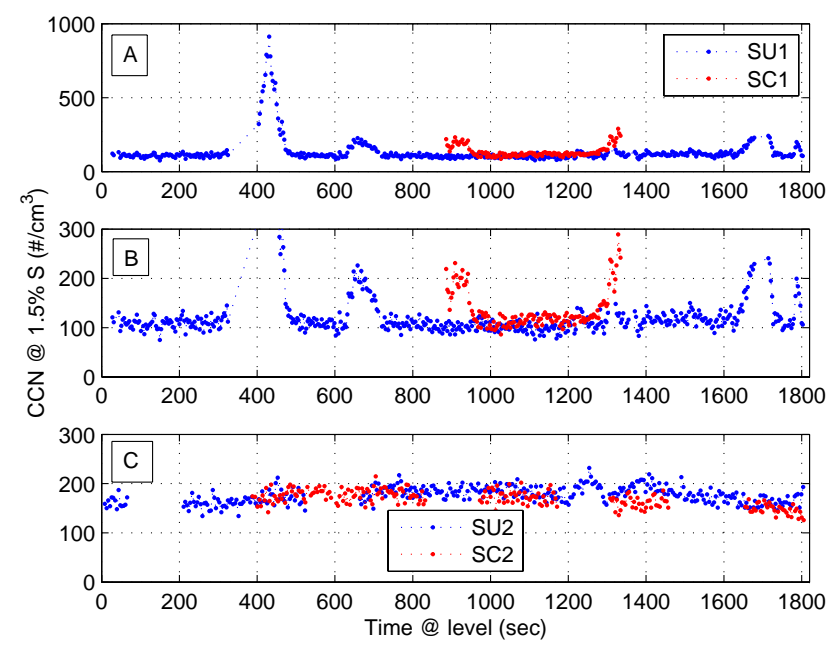

Fig. 4. Cumulative $\mathrm{CCN}$ at $1.5 \%$ supersaturation for the CBL circles of RICO RF14 excluding the periods of precipitation. Panel (B) shows an expanded scale of (A).

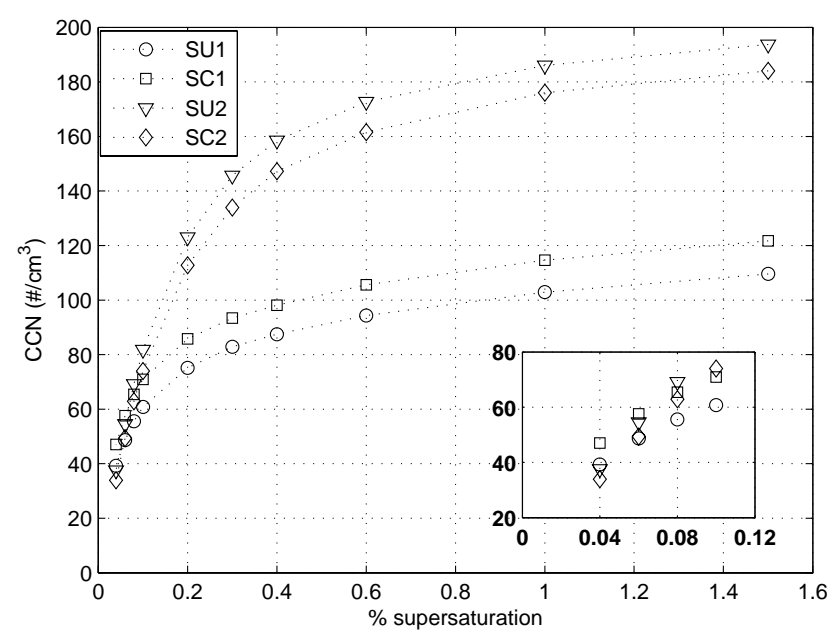

Fig. 5. Mean $\mathrm{CCN}$ cumulative concentrations as a function of supersaturation from the four CBL circles for periods free of $\mathrm{SO}_{2}$ pollution and precipitation.

SU1 and SU2. Over the same time period mean DMS concentrations decreased from $87 \mathrm{pptv}$ for SU1 to $66 \mathrm{pptv}$ during $\mathrm{SU} 2$. With a unit production efficiency of $\mathrm{SO}_{2}$ from DMS, an upper limit to the increase in $\mathrm{SO}_{2}$ would have been $21 \mathrm{pptv}$ assuming upwind sources of DMS and the CBL conditions were similar throughout the time period. A lower limit for a DMS source of $\mathrm{SO}_{2}$ could be as low as $15 \mathrm{pptv}$ of $\sim 0.7$ (Bandy et al., 1996; Davis et al., 1999). Consequently, DMS could have provided a source of $\mathrm{SO}_{2}$ that could balance $\mathrm{SO}_{2}$ losses to convection and reactions that could support the increased concentrations of $\mathrm{CCN}$ at supersaturations of $0.2 \%$ to $0.6 \%$. While the details for the homogenous formation and oxidation of DMS to $\mathrm{SO}_{2}$ to sulfuric acid have been 


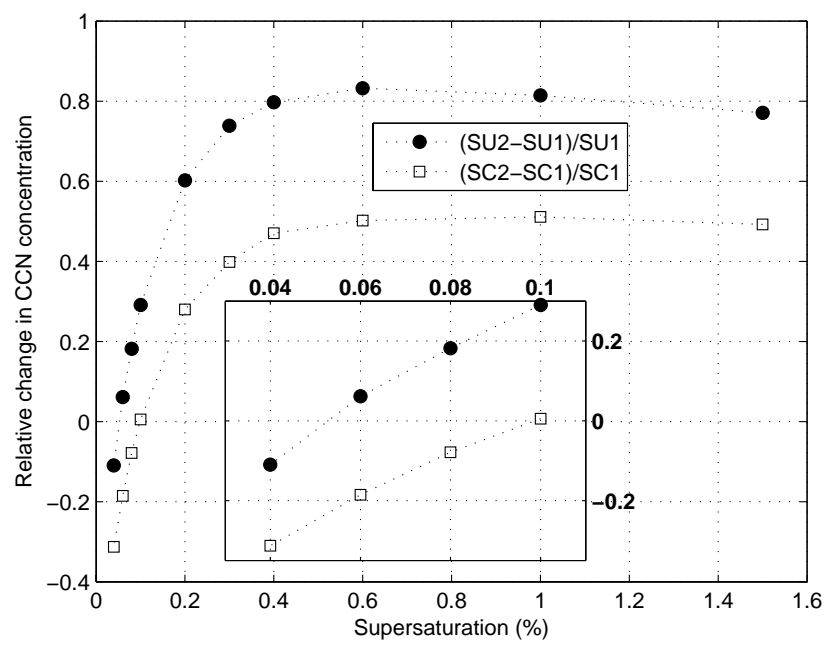

Fig. 6. Change in the cumulative $\mathrm{CCN}$ means for the late afternoon circles relative to the midday circles for the periods free of $\mathrm{SO}_{2}$ precipitation and pollution.

established in the remote marine CBL (Davis et al., 1999), the demonstration of the details of the formation of Aitken nuclei from this gas phase processing remain incomplete because of the difficulty of the measurements within the CBL, although evidence for the formation of particles of a few nanometers diameter has been demonstrated (Weber et al., 2001).

The increases in $\mathrm{CCN}$ concentrations at $0.2 \%$ to $0.6 \%$ supersaturation during SU2 and SC2 circles compared to earlier are consistent with the PCASP probe spectra. Aerosols for diameters of 0.14 to $0.185 \mu \mathrm{m}$ had concentrations twice as great as the earlier circles (Fig. 4). Accumulation mode aerosols are primarily ammonium sulfate in the remote marine $\mathrm{CBL}$ as deduced from volatility measurements. The PCASP spectra showed no significant change for sizes $>0.5 \mu \mathrm{m}$ between the early and later CBL circles (Fig. 4). These larger sized aerosols are typically dominated by sea salt. The production of sea salt aerosols is well known to be a strong function of surface wind speed. With wind speeds of 12 to $15 \mathrm{~m} \mathrm{~s}^{-1}$ during all CBL circles (the highest during the RICO flights), the number concentrations of salt aerosols generated from sea spray would be expected to be similar throughout the day. Sea spray derived salt aerosols would produce $\mathrm{CCN}$ that activated at the lowest supersaturations $(\leq 0.1 \%)$, which corresponded to sizes $>0.1 \mu \mathrm{m}$ diameter based on the in flight calibration. However, CCN concentrations that activated at $<0.1 \%$ were generally lower in the later circles compared to earlier with SC2 circle affected the most (Fig. 6 inset).

\section{3 $\mathrm{SO}_{2}$ and $\mathrm{CCN}$ correlations}

In two periods during RF14 there were linear correlations of $\mathrm{SO}_{2}$ with $\mathrm{CCN}$ and of $\mathrm{CN}$ with $\mathrm{CCN}$ over a wide range of concentrations and supersaturations. While the latter correlation is expected, the former has not previously been observed in the marine atmosphere with a time resolution of the $\mathrm{SO}_{2}$ measurements much greater than for $\mathrm{CCN}$ measurements. Furthermore, the correlations between $\mathrm{SO}_{2}$ and $\mathrm{CCN}$ increased as the supersaturation increased.

For the period of the SU1 circle most impacted by ship exhaust (400 to $500 \mathrm{~s}$ of Figs. 1, 4), $\mathrm{SO}_{2}$ ranged from 50 to 600 pptv with concomitant changes in $\mathrm{CN}$ and $\mathrm{CCN}$. $\mathrm{SO}_{2}$ and $\mathrm{CCN}$ were linearly correlated at all supersaturations (Fig. 7; Table 4), although the correlation coefficients decreased slightly with supersaturations $<0.2 \%$. There were similar correlations between $\mathrm{CN}$ and $\mathrm{CCN}$ for this period (Table 4).

For the $\mathrm{SU} 1$ case, the production of $\mathrm{SO}_{2}$ and primary sulfate aerosols in the combustion process would be responsible for the correlation of $\mathrm{SO}_{2}$ and $\mathrm{CCN}$ over the wide range of supersaturations. During combustion oxidation of $\mathrm{SO}_{2}$ to sulfuric acid and adsorption of $\mathrm{SO}_{2}$ and sulfuric acid on to soot particles would form externally mixed aerosols that would have a strong influence on the larger $\mathrm{CCN}$ with supersaturations $\leq 0.1 \%$. Addition of $\mathrm{SO}_{2}$ and sulfuric acid to salt aerosols would also contribute the correlations with the larger CCN with supersaturations $\leq 0.1 \%$. Downwind of the source a large number of small aerosols could be produced by further oxidation of $\mathrm{SO}_{2}$ through homogeneous reactions to sulfuric acid and heterogeneous reactions in aerosols by $\mathrm{H}_{2} \mathrm{O}_{2}$, which would be aided by neutralization from gas phase ammonia and acidity reductions by hydrochloric acid evaporation from salt aerosols.

During the SU2 circle (1100 to 1500 of, Figs. 1, 4) $\mathrm{SO}_{2}$, $\mathrm{CN}$, and $\mathrm{CCN}$ also displayed a synchronous variation in their concentrations. Although the variation in $\mathrm{SO}_{2}$ was only 15 to $45 \mathrm{pptv}$, there was enough of a perturbation to assess the correlation of these three constituents. For $\mathrm{CCN}$ activated at $1.5 \%$ supersaturation there was a linear correlation between $\mathrm{SO}_{2}$ and $\mathrm{CCN}$ (Fig. 7; Table 4) with statistically the same slope as for the pollution case. For the intermediate supersaturations of 0.2 to $0.6 \%$ the correlation increased as the supersaturation increased (Fig. 7). There was no linear correlation between $\mathrm{SO}_{2}$ and $\mathrm{CCN}$ activated at supersaturations $\leq 0.1 \%$ (Fig. 7; Table 4). The linear correlations of $\mathrm{CN}$ and $\mathrm{CCN}$ were similar to those of $\mathrm{SO}_{2}$ and $\mathrm{CCN}$ (Table 4).

With the absence of soot particles and primary sulfates from combustion during the SU2 circle, the very low $\mathrm{SO}_{2}$ concentrations would not be sufficient to affect the CCN that activate at supersaturations $\leq 0.1 \%$ as in the pollution plume. The CCN concentrations activated at $\leq 0.1 \%$ supersaturation were similar throughout the day for all the CBL circles (Fig. 6). If these low supersaturation $\mathrm{CCN}$ were sea salt, the diameters would have been in the range of 0.1 to $0.3 \mu \mathrm{m}$ based on the in-flight calibration of the CCN spectrometer. These larger CCN of primarily sea salt would be uncorrelated to $\mathrm{SO}_{2}$. 
Table 4. Linear regressions of $\mathrm{CCN}\left(\# \mathrm{~cm}^{-3}\right)$ on $\mathrm{SO}_{2}$ (pptv) or $\mathrm{CN}\left(\# \mathrm{~cm}^{-3}\right.$ ) for two CBL events. SU1: Period 395 to $475 \mathrm{~s}$ for a pollution event $(n=24)$. SU2: Period 1200 to $1500 \mathrm{~s}$ in the absence of pollution $(n=65)$.

\begin{tabular}{lrrrrrrrr}
\hline & \multicolumn{3}{c}{$\mathrm{SO}_{2}$} & \multicolumn{3}{c}{$\mathrm{CN}$} \\
\hline & \multicolumn{2}{c}{$\mathrm{SU} 1$} & \multicolumn{2}{c}{$\mathrm{SU} 2$} & \multicolumn{2}{c}{$\mathrm{SU}$} & \multicolumn{2}{c}{$\mathrm{SU} 2$} \\
& 395 to $475 \mathrm{~s}$ & 1200 to $1500 \mathrm{~s}$ & 395 to $475 \mathrm{~s}$ & 1200 to $1500 \mathrm{~s}$ \\
\hline Supersaturation & $1.5 \%$ & $0.1 \%$ & $1.5 \%$ & $0.1 \%$ & $1.5 \%$ & $0.1 \%$ & $1.5 \%$ & $0.1 \%$ \\
Slope & 1.35 & 0.73 & 1.69 & 0.081 & 0.60 & 0.31 & 0.61 & 0.06 \\
Std. dev of slope & 0.08 & 0.08 & 0.29 & 0.21 & 0.05 & 0.05 & 0.11 & 0.08 \\
Correlation coeff. & 0.96 & 0.89 & 0.59 & 0.048 & 0.92 & 0.82 & 0.58 & 0.10 \\
\hline
\end{tabular}

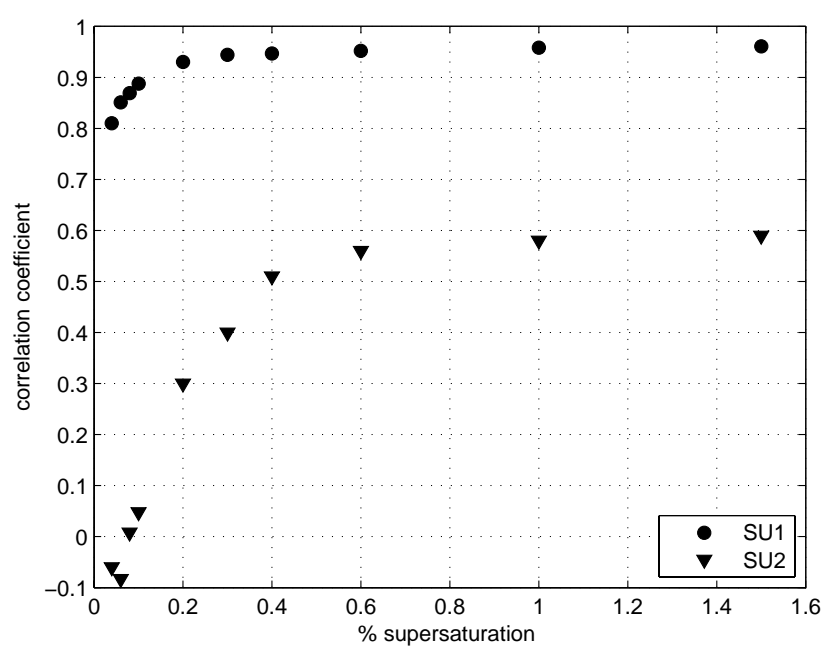

Fig. 7. Correlation coefficients for linear regressions of CCN number concentrations at various supersaturations on $\mathrm{SO}_{2}$ concentrations. SU1: a pollution plume from $400 \mathrm{~s}$ to $500 \mathrm{~s}$ of circle at $90 \mathrm{~m}$. SU2: for the period $1200 \mathrm{~s}$ to $1500 \mathrm{~s}$ of the circle at $90 \mathrm{~m}$ in the absence of pollution.

The increasing correlation between $\mathrm{SO}_{2}$ and $\mathrm{CCN}$ activating at $\geq 0.2 \%$ supersaturation (Fig. 7) could be the result of $\mathrm{SO}_{2}$ conversion to sulfate or $\mathrm{SO}_{2}$ uptake by existing small $\mathrm{CCN}$ or by pre-CCN Aitken aerosols which were activated by reaction with $\mathrm{SO}_{2}$. The $\mathrm{CCN}$ concentrations at supersaturations $>0.1 \%$ in the late CBL circles provided more than half of the total number of $\mathrm{CCN}$ (Fig. 5) with a leveling off at $0.6 \%$ supersaturation.

The source of the increased CCN may not be solely in the $\mathrm{CBL}$. Ozone covaried with $\mathrm{SO}_{2}, \mathrm{CN}$, and $\mathrm{CCN}$ for this period on $\mathrm{SU} 2$, although with a lag time of unknown origin. Because $\mathrm{O}_{3}$ is destroyed in the CBL, the $\mathrm{O}_{3}$ increases must have been from above the CBL. Water vapor MR and DMS were anticorrelated to the changes in $\mathrm{SO}_{2}, \mathrm{O}_{3}, \mathrm{CCN}$, and $\mathrm{CN}$ for this period. Increases in DMS and water vapor MR indicated updrafts from very near the surface. Decreases in water vapor MR indicated that the air parcels would have come from cooler, drier air above. Lower DMS concentrations also indicated entrainment of air from the cloud layer of the trade wind where DMS concentrations are typically lower than the CBL (Conley et al., 2009; Davis et al., 1999; Russell et al., 1998). At the time of the these measurements (Table 1) the solar zenith angle was $>80^{\circ}$, which makes homogeneous oxidation of DMS to $\mathrm{SO}_{2}$ initiated by hydroxyl radical negligible.

The sum of these measurements points toward subsidence of air parcels from the entrainment zone between the top of the CBL and the cloud base. For this period SU2 only cumulus congestus clouds were visible on the forward video of the aircraft. The peaks in the DMS and water vapor concentrations corresponded to the time periods when clouds were directly overhead as indicated by the upward viewing infrared radiometer. Updrafts related to these clouds must have been responsible for the upward flux of DMS and water vapor. $\mathrm{SO}_{2}$ concentrations $\leq 20 \mathrm{pptv}$ (near $1180 \mathrm{~s}$ and after $1500 \mathrm{~s}$ of SU2 in Fig. 1) occurred where many small non-precipitating clouds were overhead. Conversely, the peaks in $\mathrm{SO}_{2}, \mathrm{CCN}$, and $\mathrm{CN}$ concentrations occurred when there were no clouds overhead. Entrainment of $\mathrm{SO}_{2}, \mathrm{CCN}$, and $\mathrm{CN}$ appeared to be responsible for the observed increases.

\section{Conclusions}

Correlations between $\mathrm{SO}_{2}$ and $\mathrm{CCN}$ at supersaturations $>0.2 \%$ in the CBL were found which are consistent with $\mathrm{SO}_{2}$ being a primary source of the smallest CCN. In the absence of a pollution source of $\mathrm{SO}_{2} \mathrm{CCN}$ were only correlated with $\mathrm{SO}_{2}$ at supersaturations above $0.2 \%$ with strongest correlations $\geq 0.6 \%$ supersaturation. Evidence of entrainment of $\mathrm{CCN}$ from the cloud layer into the CBL was found in precipitation free regions near sunset.

The concentrations of $\mathrm{CCN}$ at supersaturations $>0.2 \%$ and aerosols with diameters $<0.2 \mu \mathrm{m}$ were markedly higher in the late afternoon compared to the midday period. The difference appeared to be related the occurrence of precipitation during the midday even when comparing precipitation free regions for the two CBL sampling periods. Because 
the concentrations of $\mathrm{CCN}$ at supersaturations $\leq 0.1 \%$ were similar for both periods and the concentrations of $\mathrm{CCN}$ at supersaturations of $0.2 \%$ to $0.6 \%$ were much lower during the midday period, $\mathrm{CCN}$ supersaturations of $0.2 \%$ to $0.6 \%$ appeared to have a greater role in formation of clouds that precipitate. Hudson and Noble (2009) found that cloud drop concentrations were well correlated to $\mathrm{CCN}$ activated at $1 \%$ supersaturation for the surface flight levels. The mean effective supersaturation for the surface circles during RICO was $0.5 \%$ with a range of $0.2-1.5 \%$ supersaturation. This is similar to the range found for stratocumulus cloud decks with mean $\mathrm{CCN}$ that activate at $1 \%$ supersaturation (Hudson et al., 2010).

Acknowledgements. Support from the National Science Foundation under grants ATM-0342138, ATM-0627227, ATM-0627227, and ATM-0342618 is gratefully acknowledged. National Center for Atmospheric Research (NCAR) is sponsored by the National Science Foundation. We thank the NCAR Research Aviation Facility for their assistance throughout the C-130 operation phase of RICO. Data from the RICO project archive at NCAR Earth Observing Laboratory archive for the C-130 and the Radar Image Archive for the radar images for RF14 are gratefully acknowledged.

Edited by: R. Krejci

\section{References}

Arthur, D. K., Lasher-Trapp, S., Abdel-Haleem, A., Klosterman, N., and Ebert, D. S.: A new three-dimensional visualization system for combining aircraft and radar data and its application to RICO observations, J. Atmos. Oceanic Tech., 27, 811-828, doi:10.1175/2009JTECHA1395.1, 2010.

Bandy, A. R., Thornton, D. C., and Driedger, A. R.: Airborne measurements of sulfur dioxide, dimethyl sulfide, carbon disulfide, and carbonyl sulfide by isotope dilution gas chromatography mass spectrometry, J. Geophys. Res.-Atmos., 98, 23423-23433, 1993.

Bandy, A. R., Thornton, D. C., Blomquist, B. W., Chen, S., Wade, T. P., Ianni, J. C., Mitchell, G. M., and Nadler, W.: Chemistry of dimethyl sulfide in the equatorial Pacific atmosphere, Geophys. Res. Lett., 23, 741-744, 1996.

Capaldo, K., Corbett, J. J., Kasibhatla, P., Fischbeck, P., and Pandis, S. N.: Effects of ship emissions on sulphur cycling and radiative climate forcing over the ocean, Nature, 400, 743-746, 1999.

Colon-Robles, M., Rauber, R. M., and Jensen, J. B.: Influence of low-level wind speed on droplet spectra near cloud base in trade wind cumulus, Geophys. Res. Lett., 33, L20814, doi:10.1029/2006GL027487, 2006.

Conley, S. A., Faloona, I., Miller, G. H., Lenschow, D. H., Blomquist, B., and Bandy, A.: Closing the dimethyl sulfide budget in the tropical marine boundary layer during the Pacific Atmospheric Sulfur Experiment, Atmos. Chem. Phys., 9, 87458756, doi:10.5194/acp-9-8745-2009, 2009.

Davis, D., G., C., Bandy, A., Thornton, D., Eisele, F., Mauldin, L., Tanner, D., Lenschow, D., Fuelberg, H., Huebert, B., Heath, J., Clarke, A., and Blake, D.: Dimethyl sulfide oxidation in the equatorial Pacific: comparison of model simulations with field observations for DMS, $\mathrm{SO}_{2}, \mathrm{H}_{2} \mathrm{SO}_{4}(\mathrm{~g}), \mathrm{MSA}(\mathrm{g}), \mathrm{MS}$ and NSS, J. Geophys. Res.-Atmos., 104, 5765-5784, 1999.

Gerber, H. E., Frick, G. M., Jensen, J. B., and Hudson, J. G.: Entrainment, mixing, and microphysics in trade-wind cumulus, J. Meteorol. Soc. Jpn., 86, 87-106, 2008.

Hudson, J. G. and Mishra, S.: Relationships between CCN and cloud microphysics variations in clean maritime air, Geophys. Res. Lett., 34, L16804, doi:10.1029/2007GL030044, 2007.

Hudson, J. G. and Noble, S.: CCN and cloud droplet concentrations at a remote ocean site, Geophys. Res. Lett., 36, L13812, doi:10.1029/2009g1038465, 2009.

Hudson, J. G., Noble, S., and Jha, V.: Stratus cloud supersaturations, Geophys. Res. Lett., 37, L21813, doi:10.1029/2010g1045197, 2010.

Hudson, J. G., Jha, V., and Noble, S.: Drizzle correlations with giant nuclei, Geophys. Res. Lett., 38, L05808 doi:10.1029/2010g1046207, 2011.

Lowenstein, J. H., Blyth, A. M., and Lawson, R. P.: Early evolution of the largest-sized droplets in maritime cumulus clouds, Q. J. Roy. Meteor. Soc., 136, 708-717, doi:10.1002/qj.597, 2010.

Rauber, R. M., Stevens, B., Ochs, H. T., Knight, C., Albrecht, B. A., Blyth, A. M., Fairall, C. W., Jensen, J. B., Lasher-Trapp, S. G., Mayol-Bracero, O. L., Vali, G., Anderson, J. R., Baker, B. A., Bandy, A. R., Burnet, E., Brenguier, J. L., Brewer, W. A., Brown, P. R. A., Chuang, P., Cotton, W. R., Di Girolamo, L. D., Geerts, B., Gerber, H., Goke, S., Gomes, L., Heikes, B. G., Hudson, J. G., Kollias, P., Lawson, R. P., Krueger, S. K., Lenschow, D. H., Nuijens, L., O’Sullivan, D. W., Rilling, R. A., Rogers, D. C., Siebesma, A. P., Snodgrass, E., Stith, J. L., Thornton, D. C., Tucker, S., Twohy, C. H., and Zuidema, P.: Electronic supplement to Rain in (shallow) Cumulus over the Ocean - The RICO campaign, B. Am. Meteorol. Soc., 88, S12-S18, 2007a.

Rauber, R. M., Stevens, B., Ochs, H. T., Knight, C., Albrecht, B. A., Blyth, A. M., Fairall, C. W., Jensen, J. B., Lasher-Trapp, S. G., Mayol-Bracero, O. L., Vali, G., Anderson, J. R., Baker, B. A., Bandy, A. R., Burnet, E., Brenguier, J. L., Brewer, W. A., Brown, P. R. A., Chuang, P., Cotton, W. R., Di Girolamo, L. D., Geerts, B., Gerber, H., Goke, S., Gomes, L., Heikes, B. G., Hudson, J. G., Kollias, P., Lawson, R. P., Krueger, S. K., Lenschow, D. H., Nuijens, L., O'Sullivan, D. W., Rilling, R. A., Rogers, D. C., Siebesma, A. P., Snodgrass, E., Stith, J. L., Thornton, D. C., Tucker, S., Twohy, C. H., and Zuidema, P.: Rain in shallow cumulus over the ocean - The RICO campaign, B. Am. Meteorol. Soc., 88, 1912-1928, 2007b.

Reiche, C. H. and Lasher-Trapp, S.: The minor importance of giant aerosol to precipitation development within small trade wind cumuli observed during RICO, Atmos. Res., 95, 386-399, 2010.

Russell, L. M., Lenschow, D. H., Laursen, K. K., Krummel, P. B., Siems, S. T., Bandy, A. R., Thornton, D. C., and Bates, T. S.: Bidirectional mixing in an ACE 1 marine boundary layer overlain by a second turbulent layer, J. Geophys. Res.-Atmos., 103, 16411-16432, doi:10.1029/97jd03437, 1998.

Snodgrass, E. R., Di Girolamo, L., and Rauber, R. M.: Precipitation characteristics of trade wind clouds during RICO derived from radar, satellite, and aircraft measurements, J. Appl. Meteorol. Climatol., 48, 464-483, 2009.

Thornton, D. C., Bandy, A. R., Beltz, N., Driedger, A. R., and Ferek, R.: Advection of sulfur dioxide over the western Atlantic Ocean during CITE-3, J. Geophys. Res.-Atmos., 98, 23459- 
23467, 1993.

Thornton, D., Bandy, A., Blomquist, B., Driedger, A., and Wade, T.: Sulfur dioxide distribution over the Pacific Ocean 1991-1996, J. Geophys. Res.-Atmos., 104, 5845-5854, 1999.

Thornton, D., Bandy, A., Tu, F., Blomquist, B., Mitchell, G., Nadler, W., and Lenschow, D.: Fast airborne sulfur dioxide measurements by atmospheric pressure ionization mass spectrometry (APIMS), J. Geophys. Res.-Atmos., 107, 4632 doi:10.1029/2002JD002289, 2002.
Tu, F. H., Thornton, D. C., Bandy, A. R., Carmichael, G. R., Tang, Y., Thornhill, K. L., Sachse, G. W., and Blake, D. R.: Longrange transport of sulfur dioxide in the central Pacific, J. Geophys. Res.-Atmos., 109, D15S08, doi:10.1029/2003JD004309, 2004.

Weber, R. J., Chen, G., Davis, D. D., Mauldin, R. L., Tanner, D. J., Eisele, F. L., Clarke, A. D., Thornton, D. C., and Bandy, A. R.: Measurements of enhanced $\mathrm{H} 2 \mathrm{SO} 4$ and 3-4 nm particles near a frontal cloud during the First Aerosol Characterization Experiment (ACE 1), J. Geophys. Res. Atmos., 106, 24107-24117, 2001. 